\title{
Performance Analysis of Axial and Mixed Flow Turbines: A Comparative Study
}

\author{
Prof. Ruchi Khare ${ }^{1}$ Prof. Vishnu Prasad ${ }^{2}$ \\ ${ }^{1,2}$ (Department, of Civil Engineering / Maulana Azad National Institute of Technology,Bhopal, India)
}

\begin{abstract}
The reaction turbines have application for very wide range of hydro power projects. Turbine is the most important component of hydro power plant. Its cost varies 15-35\% of the total cost of hydropower project. The analysis of flow behavior of turbine under various operating conditions for cost effective design of the turbine is utmost importance. The model testing of turbine gives overall performance of turbines based on global parameters. This approach is very costly and time consuming. The computational fluid dynamics compliments experimental and theoretical approach by providing an alternate cost effective means of simulating real turbulent flow. In the present paper, the numerical flow simulation of axial and mixed flow turbine has been carried out to study the effect of operating conditions on the local and global parameters of turbine. The simulation results for efficiency and output bear close comparison with experimental results.
\end{abstract}

Keywords: axial flow turbine, CFD, mixed flow turbine, reaction turbines, runner

\section{Introduction}

The selection of turbine and its capacity for any particular site depends on head and discharge available. Reaction turbine is the most widely used turbine for wide range of head and discharge. Reaction turbines are classified as mixed flow (Francis turbine) and axial flow (Propeller Kaplan turbines). The Francis and propeller runners have fixed blades and Kaplan runner has adjustable blade [1]. Theses turbines are mounted horizontally or vertically depending on the operational requirements. The performance characteristics of Kaplan and Francis turbines vary because of different flow direction in runner and its construction.

The design and development of reaction turbines affect significantly the overall performance of the hydro power stations and it requires continuous research and development in this field. The improvement in the local and global performance i.e, efficiency, losses etc through model testing can be done only up to limited extent because of time, cost and experimental facility constraints [4]. The numerical flow simulation by using CFD codes is cost effective tool to solve this problem, because it can provide not only variation patterns of local and global parameter but also gives flexibility to change the design of different components and predict its performance without actual construction [11]. In present paper, the performance of existing Francis and Kaplan turbine is compared for their local and global characteristics. The efficiency results obtained from numerical simulations for both type of turbines are found in good agreement with experimental values.

\section{Geometric Modeling}

The geometry of flow space is one of the important input for numerical simulation. The turbine flow space is complicated and therefore modeling of the turbines as whole in one go is a very difficult task. Hence axial and mixed flow turbines are modeled in parts, namely casing, stay ring, guide wheel, runner and draft tube separately and then assembled through interfaces for simulation. The solid modeling of different components of turbine is done using ANSYS Workbench. The assembled 3D geometry of Francis \& Kaplan turbine are shown in fig. 1 and fig. 2 respectively.

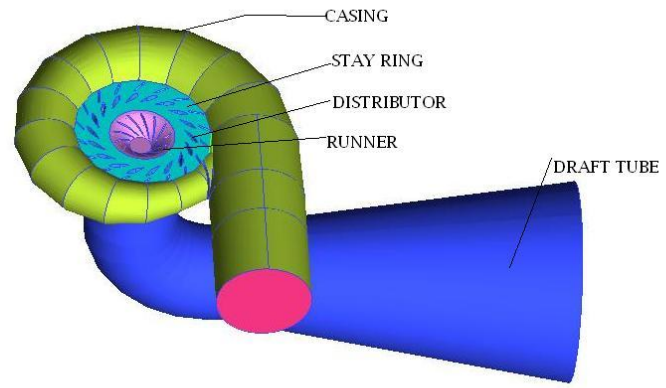

Fig. 1: 3-D assembly of Francis turbine of specific speed $266.19 \mathrm{~m}-\mathrm{kW}$ 




Fig. 2: 3-D assembly of Kaplan turbine of specific speed $300.34 \mathrm{~m}-\mathrm{Kw}$

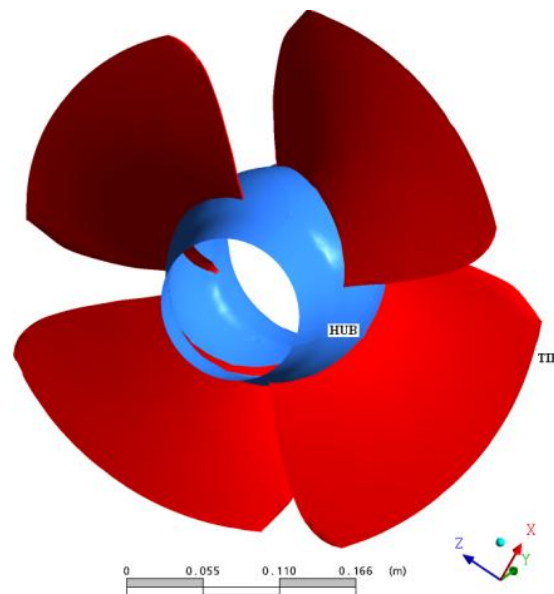

(a) Kaplan Turbine

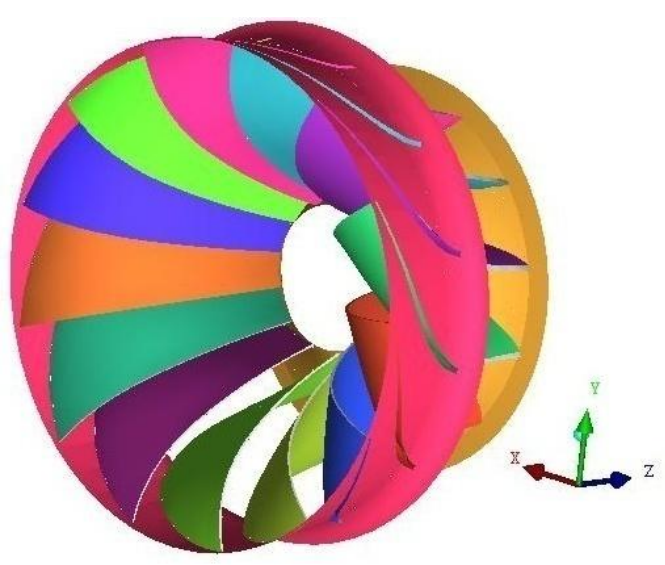

(b) Francis Turbine

Fig. 3 Runners of axial and mixed flow turbines

The existing Kaplan Turbine is of $400 \mathrm{~mm}$ diameter with 4 blades whereas the Francis runner is of $1010 \mathrm{~mm}$ diameter with 13 blades of. Both the turbines are horizontal axis.

The tetrahedral and prismatic mesh in flow domain and triangular mesh at surface is generated for both turbines. The mesh of Kaplan turbine space has 42084369 elements and Francis turbine is dicretized in 78468166 elements. The Y+ value is kept within recommended value for automatic wall function SST к- $\omega$ turbulence model.

\section{Boundary condition}

The flow characteristics inside turbine space are greatly affected by nature of boundary and values of input parameters at boundaries and lead change in performance of turbine [5]. Therefore, the specification of boundary condition plays an important role in accuracy of results obtained from computational fluid dynamics. The following boundary conditions are given in present simulation:

\section{Inlet boundary condition:}

The mass flow rate is specified at the casing inlet according to guide vane opening.

\section{Outlet boundary condition:}

The average static pressure at the outlet of draft tube is specified.

\section{Turbulence model:}

The SST $\kappa-\omega$ turbulence model has been used due to passage curvature and runner rotation.

\section{Rotational speed:}

The runner is only rotating component in turbine and different rotational speed for each guide vane opening are specified to vary the operating regime of turbine. The casing, stay vane, guide vane and draft tube domain are set stationary in both Francis and Kaplan turbine analysis. 


\section{Wall conditions:}

The walls of all flow domains are assumed to be impervious and smooth and no slip condition is selected. The simulation is carried out by using high resolution scheme.

\section{Formulae Used}

The values of pressure and velocities obtained at element nodes from numerical simulation are used to compute the mass average values of local and global dimensionless parameters [3].

$$
\begin{array}{ll}
\text { Meridional velocity coefficient } & c_{m}=\frac{C_{M}}{\sqrt{2 g H}} \\
\text { Whirl velocity coefficient } & c_{u}=\frac{C_{U}}{\sqrt{2 g H}} \\
\text { Specific energy coefficient } & \kappa=\frac{g D^{4}}{Q^{2}} \\
\text { Blade circulation coefficient } & \tau=\frac{t\left(C_{U 1}-C_{U 2}\right)}{D \sqrt{2 g H}} \\
\text { Speed factor } & S F=\frac{n D}{\sqrt{g H}} \\
\text { Discharge factor } & D F=\frac{Q^{2}}{D^{2} \sqrt{g H}} \\
\text { Efficiency } & \eta_{h}=\frac{H_{R} * 100}{H^{2}} \\
\text { Degree of reaction for Kaplan turbine } & \varphi=\frac{W_{2}^{2}-W_{1}^{2}}{2 g H_{n}} \\
& \varphi=\frac{W_{2}^{2}-W_{1}^{2}}{2 g H_{n}}+\frac{U_{1}^{2}-U_{2}^{2}}{2 g H_{n}}
\end{array}
$$

\section{Results And Discussions}

The numerical flow simulation in both the turbines has been carried out for three guide vane opening at different rotational speeds. The guide vane openings of Francis turbine are $41^{\circ}, 45.5^{\circ}, 48.2^{\circ}$ which are symbolized as $\alpha 1 \mathrm{f}, \alpha 2 \mathrm{f}, \alpha 3 \mathrm{f}$ respectively in graphical representations. The guide vane openings of Kaplan turbine are $35^{\circ}, 40^{\circ}$ and $50^{\circ}$ which are symbolized as $\alpha 1 \mathrm{k}, \alpha 2 \mathrm{k}, \alpha 3 \mathrm{k}$ respectively in graphical representations. The speed factor varies from 15-40 for Francis Turbine and 35-75 for Kaplan turbine. As the accuracy of CFD results depends on many factor and hence these results are to be validated with experimental results [6]. In case of hydraulic machines, experimental results are available mostly in terms of global parameters like variation of efficiency and discharge with speed. The comparison of computed and experimental efficiencies for Francis turbine and for Kaplan turbine are given in fig. 4(a) and 4(b) respectively. 


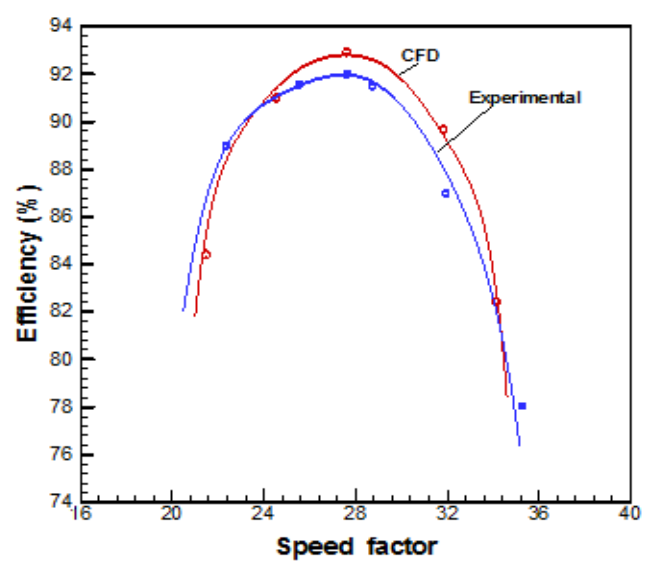

(a) Francis turbine

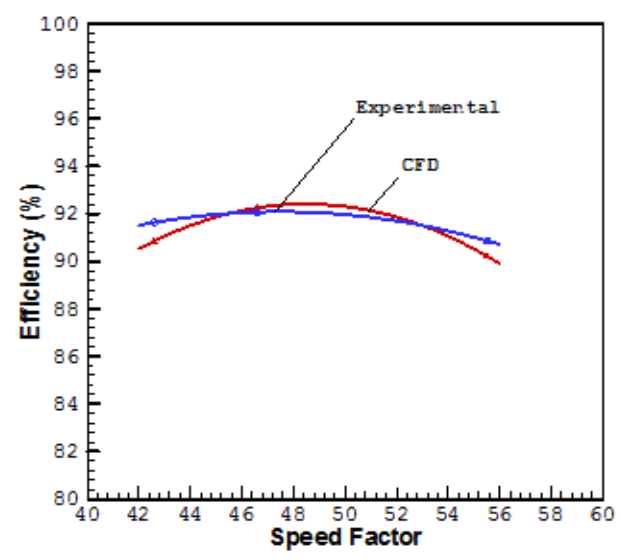

(b) Kaplan turbine

Fig. 4: Comparison of computed and experimental efficiency

It is seen from fig. 4 that the best efficiency point and efficiency pattern obtained from experimental and CFD in both turbines are closely matching. The deviation between values of efficiency obtained from numerical results and model test may be due to frictional and secondary losses are not accounted exactly in numerical flow simulation [2].

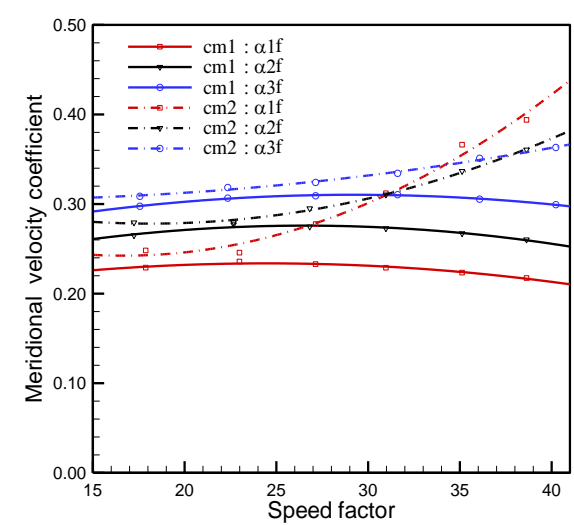

(a) Francis Turbine

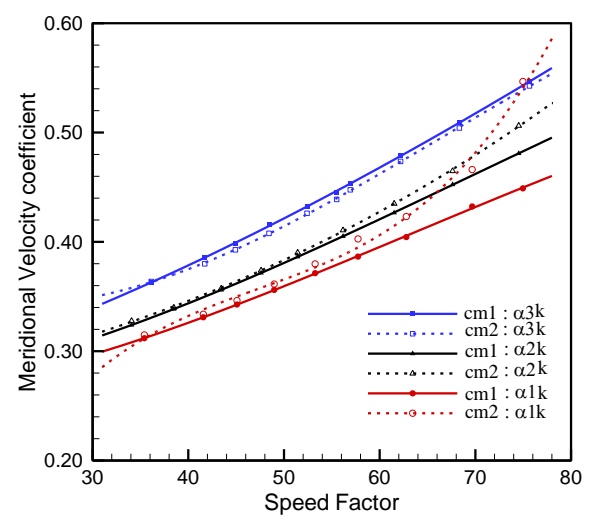

(b) Kaplan Turbine

Fig. 5: Variation of Meridional velocity

The variation of meridional velocity in fig. 5(a) indicates that in Francis turbine there is no effect of rotational speed at inlet but at outlet, it increases with speed and rate of increase is more at low guide vane opening. In Kaplan turbine fig. 5(b), meridional velocity is found to increase with speed both at inlet and outlet. The velocity increases with increase of guide vane opening in both turbines because of increased flow $[7,8]$.

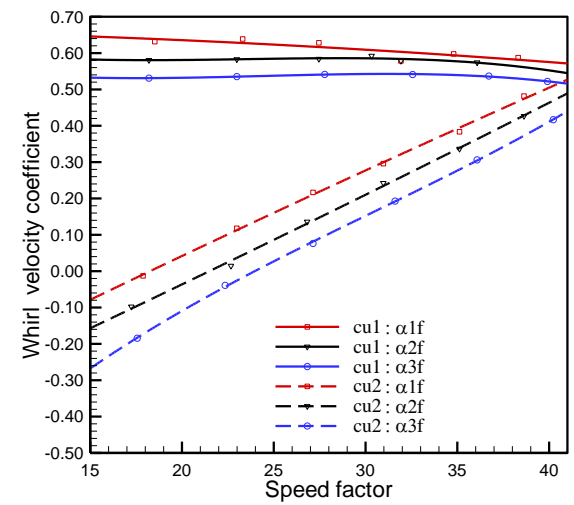

(a) Francis Turbine

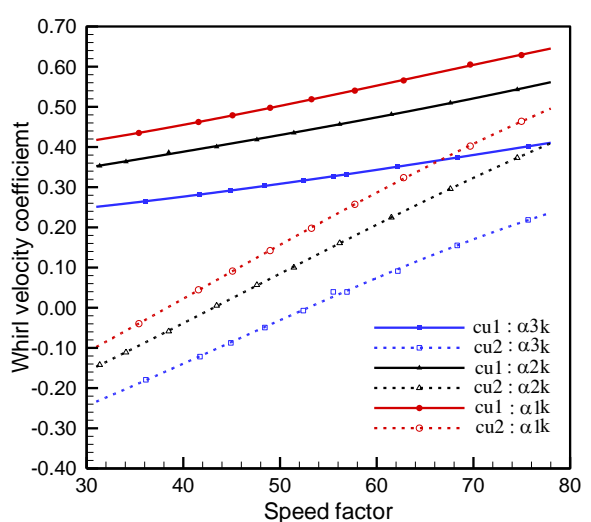

(b) Kaplan Turbine

Fig. 6: Variation of whirl velocity 


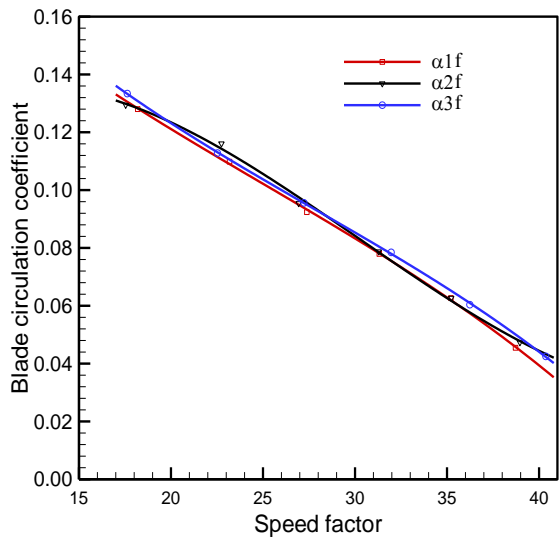

(a) Francis Turbine

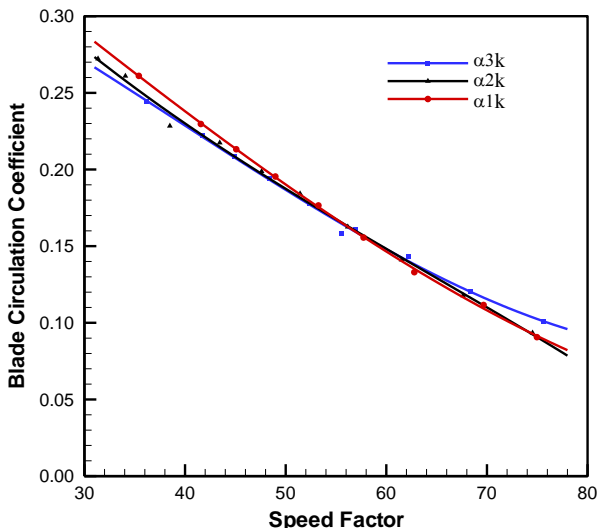

(b) Kaplan Turbine

Fig. 7: Variation of Blade circulation coefficient

The whirl velocity plot in fig. 6(a) and 6(b) predicts that this velocity at inlet is nearly independent of speed in Francis turbine while increases in Kaplan turbine. The whirl velocity increases with speed at outlet and decreases both at inlet and outlet with increase in guide vane opening in Francis as well as Kaplan turbines [9].

It is seen in fig. 7(a) and 7(b) blade circulation is nearly independent of guide vane but decreases with increase in speed in both turbines.

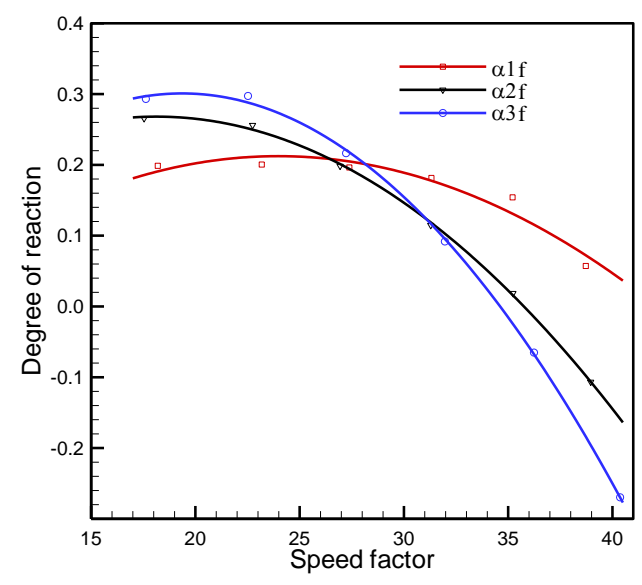

(a) Francis Turbine



(b) Kaplan Turbine

Fig. 8: Variation of degree of reaction

The degree of reaction is found to be dependent on runner speed as well as guide vane opening in both turbines as shown in fig. 8(a) and 8(b). It decreases with speed and rate of decrease is more at higher guide vane opening. This is due to large variation of relative velocity at lower guide vane opening with speed. The discharge factor variation in Francis turbine with speed is negligible but increases with guide vane opening while in case of Kaplan turbine it increases with increase in both speed and guide vane opening as seen in fig. 9(a) and 9(b)[1]. 


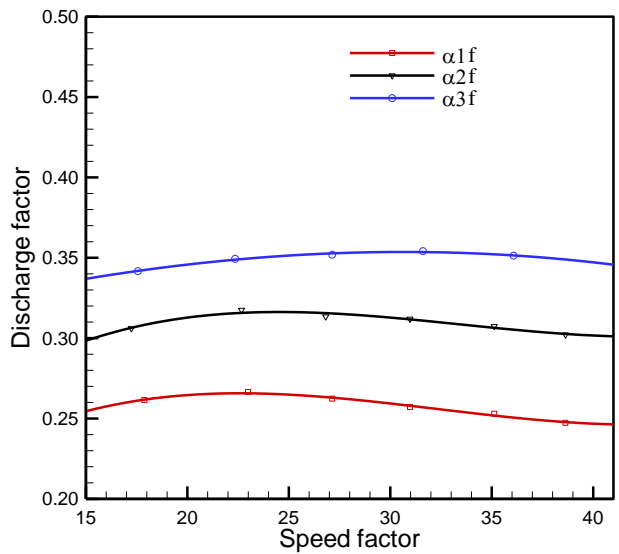

(a) Francis Turbine

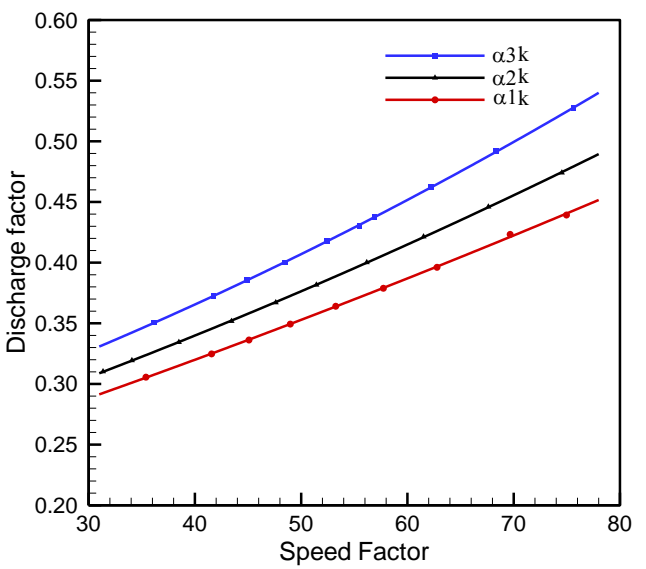

(b) Kaplan Turbine

Fig. 9: Variation of Discharge factor

The hydraulic efficiency has parabolic variation for each guide vane with maximum efficiency at different speed factors as shown in fig. 10(a) and fig. 10(b). The best efficiency is achieved at the designed guide vane opening and it is due to increased shock loss at other guide vane opening and speed factors. The value of speed factor for the best efficiency is more for Kaplan turbine as compared to Francis turbine because Kaplan is high specific speed turbine.

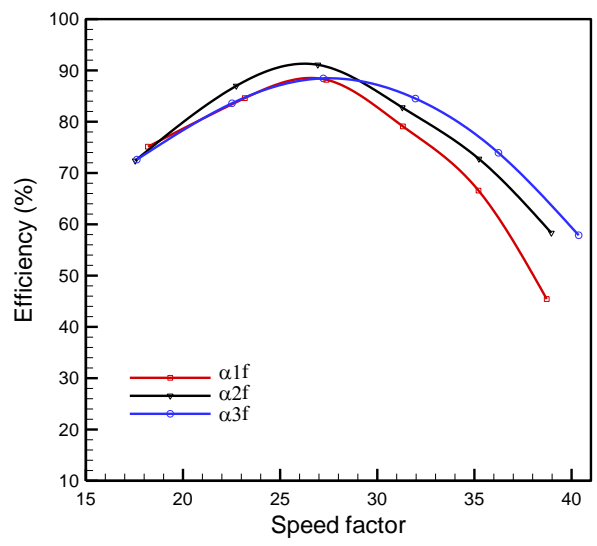

(a) Francis Turbine

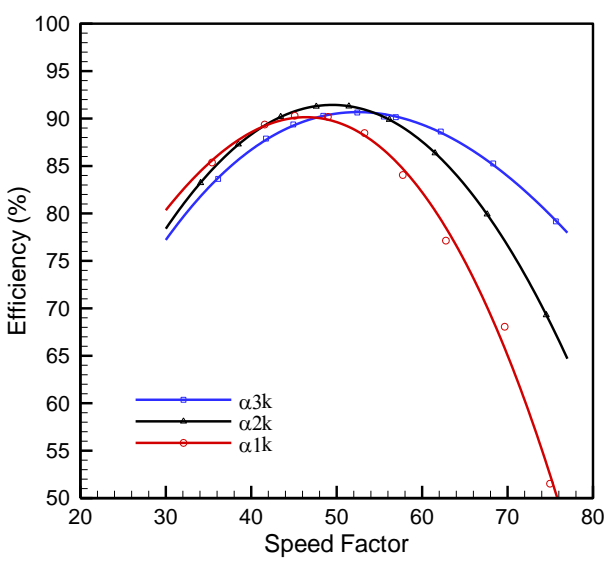

(b) Kaplan Turbine

Fig.10: Variation of Hydraulic Efficiency

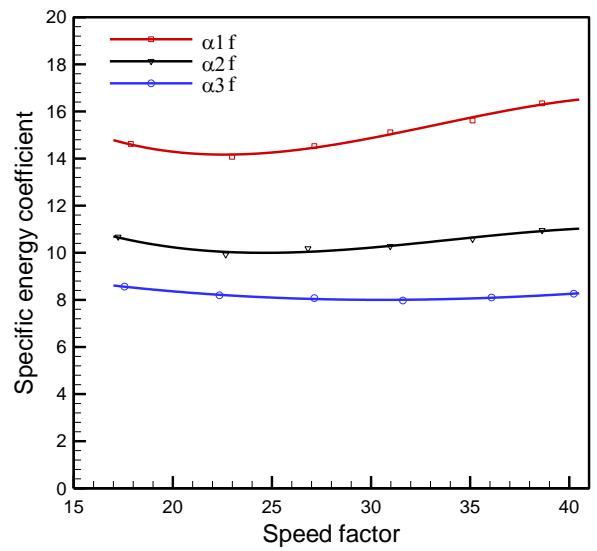

(a) Francis Turbine

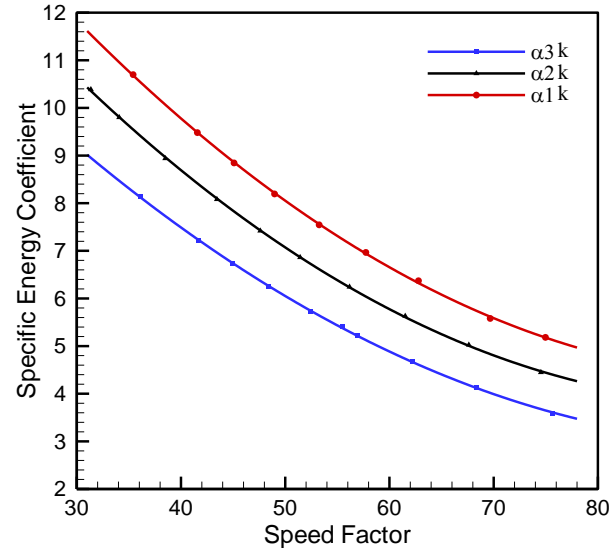

(b) Kaplan Turbine

Fig.11: Variation of Specific Energy 
It is observed from fig.11(a) and fig. 11(b) that there is slight increase in specific energy with speed in case of Francis turbine whereas in case of Kaplan turbine specific energy decreases significantly with runner speed. Secondly, specific energy at any speed increases with decrease in guide vane opening to pass the same flow through turbine. It is due to decrease in flow area at lower opening of guide vanes.

\title{
V. Conclusion
}

The efficiency and discharge variation, obtained from simulation results of both axial and mixed flow turbine closely match with the characteristics of reaction turbine obtained from experimental model test results. The discharge factor variation with speed is significant in case of Kaplan turbine where as it is nearly independent of speed in case of Francis turbine. The reduction of whirl component from inlet to outlet confirms the design features of a reaction turbine [10]. The specific energy is decreasing with increase in speed in case of Kaplan turbine but it has slight increase in case of Francis turbine. It is concluded from the study that there is significant effect of operation of turbine on most of local and global parameters of turbine and also on overall performance of turbine.

\author{
Nomenclature \\ $\mathrm{C}_{\mathrm{U}} \quad$ whirl velocity $(\mathrm{m} / \mathrm{s})$ \\ $\mathrm{C}_{\mathrm{U} 1} \quad$ whirl velocity at runner inlet $(\mathrm{m} / \mathrm{s})$ \\ $\mathrm{C}_{\mathrm{U} 2}$ whirl velocity at runner outlet $(\mathrm{m} / \mathrm{s})$ \\ $\mathrm{C}_{\mathrm{M}} \quad$ meridional velocity at runner inlet $(\mathrm{m} / \mathrm{s})$ \\ D diameter of runner (m) \\ g acceleration due to gravity $(\mathrm{m} / \mathrm{sec} 2)$ \\ $\mathrm{H}$ net head available at turbine $(\mathrm{m})$ \\ $\mathrm{H}_{\mathrm{R}} \quad$ net head utilised by runner (m) \\ $\mathrm{n} \quad$ rotational speed of runner (rpm) \\ Q volumetric flow rate $(\mathrm{m} 3 / \mathrm{s})$ \\ $t$ pitch of runner blade $(\mathrm{m})$ \\ $\mathrm{U}_{1} \quad$ peripheral velocity at runner inlet $(\mathrm{m} / \mathrm{s})$ \\ $\mathrm{U}_{2} \quad$ peripheral velocity at runner outlet $(\mathrm{m} / \mathrm{s})$ \\ $\mathrm{W}_{1} \quad$ relative velocity at runner inlet $(\mathrm{m} / \mathrm{s})$ \\ $\mathrm{W}_{2}$ relative velocity at runner outlet $(\mathrm{m} / \mathrm{s})$
}

\section{References}

[1]. Lipej ,Optimisation Method for the Design of Axial Hydraulic Turbines, Proceedings of the Institution of Mechanical Engineers Part A Journal of Power and Energy(Impact Factor: 0.6). 02/2004; 218(1):43-50(2004) DOI: 10.1243/095765004322847080

[2]. Guoyi Peng, A Practical Combined Computation Method of Mean Through- Flow for 3D Inverse Design of Hydraulic Turbo machinery Blades, Journal of Fluids Engineering, Vol. 127(6), pp 1183-1190(2005),DOI:10.1115/1.2062787

[3]. Prasad Vishnu, Gehlot V.K., Krishnamachar P.,CFD approach for design optimisation and validation for axial flow hydraulic turbine, Indian Journal of Engineering and Material Science, Vol.16(4) ,pp. 229-236(2009)

[4]. Saeed R.A., Galybin A.N. and Popov V.,Modeling of Flow Induced Stresses in a Francis Turbine Runner, Advances in Engineering Software, Elsevier Science Ltd. Oxford, UK, Volume 41 Issue 12, December, 2010, pp1245-1255(2010) DOI:10.1016/j.advengsoft.2010.09.001

[5]. Santiago Latin, Garcia Manuel, Quinterio Brian and Orrego Santiago, CFD Numerical Simulations of Francis Turbine, Rev. Fac. Ing.Univ. Antioquia N. ${ }^{\circ} 51$ pp 24-33(2010)

[6]. Tridon Sylvain, Barre Stephane, Gabriel Dan Ciocan and Tomas Laurent, Experimental Analysis of the Swirling Flow in a Francis Turbine Draft Tube: Focus on Radial Velocity Component Determination, European Journal of Mechanics B/Fluids, Vol. 29, pp 321-325(2010), DOI:10.1016/j.euromechflu.2010.02.004

[7]. Singh Punit , Nestmann Franz, Exit blade geometry and part-load performance of small axial flow propeller turbines: An experimental investigation, Experimental Thermal and Fluid Science, Vol.34 (6), , pp798-811(2010)

[8]. Singh Punit, Franz Nestmann, Experimental investigation of the influence of blade height and blade number on the performance of low head axial flow turbines, Renewable Energy, 36 pp 272-281(2010), DOI:10.1016/j.renene.2010.06.033 .

[9]. Yulin Wu, Shuhong Liu, Hua-Shu Dou, Shangfeng Wu, Tiejun Chen,Numerical prediction and similarity study of pressure fluctuation in a prototype Kaplan turbine and the model turbine, Computers \& Fluids (Impact Factor: 1.53). 03/2012; 56:pp128142. (2011).DOI: 10.1016/j.compfluid.2011.12.005

[10]. Hyen-Jun Choi, Mohanmmed Asid Zullah, Hyoung-Woon Roh, Pil-Su, Sueg-Young Oh, Young-Ho Lee:CFD Validation of Performance Improvement of a 500 KW Francis Turbine, Renewable Energy, Vol..54, pp-111-123(2013), DOI:10.1016/j.renene.2012.08.049

[11]. Diaelhag Khalifa,Simulation of an axial flow turbine runner's blades using CFD, European Scientific Journal (ESJ), ISSN: 1857 7881 (Print), ISSN: 1857 - 7431 (Online),Special edition, No.3, pp 131-137(2013) 